\title{
Advocacia em saúde e as organizações não governamentais do Distrito Federal
}

Health advocacy and the non governmental organizations in Distrito Federal, Brazil

\section{Clênio M. Brito}

Administrador, Especialista em Direito Sanitário. Militante em Saúde do Trabalhador e Controle Social do SUS. Brasília, DF, Brasil.

Resumo: Objetivo: Caracterizar o perfil e a atuação das organizações não governamentais (ONGs) que atuam na defesa do direito à saúdeno Distrito Federal (Brasil). Metodologia: Pesquisa exploratória comrealização de entrevista e aplicação de formulário aos dirigentes. Resultados: Foram identificadas 33 ONGs com atuação em saúde no DF; $64 \%$ foram fundadas entre 1991 e 2005; 82\% estão localizadas em apenas duas cidades; apenas $18 \%$ têm sede própria; $73 \%$ têm menos de 500 associados; têm suas equipes compostas predominantemente de voluntários; cerca da metade não possuem empregados contratados; são financiadas predominantemente com contribuições de associados e doações de pessoas físicas; destinam o total ou parcela significativa de seus ingressos à atuação em saúde; atuam, quase que exclusivamente, na reivindicação de atendimentos na rede pública e na participação em conselhos e conferências de saúde. Conclusão: As ONGs que atuam no campo da saúde no DF atuam muito pouco em advocacy e têm a sustentabilidade de suas atividades ameaçada por problemas de infraestrutura e financiamento.

Palavras chaves: Direito à saúde; advocacia, saúde; ONGs.

Abstract: Objective: To characterize the profile and performance of non governamental organizations (NGOs) working in advocacy of the right to health in the Federal District (Brazil). Methodology: Exploratory research with interviews and forms applied to directors (managers). Results: Were identified 33 NGOs with activities in health issues. 64\% were founded between 1991 and 2005 ; $82 \%$ are located in only two cities; only $18 \%$ has its own headoffice; $73 \%$ have less than 500 members; its teams are composed predominantly of volunteers; nearly half do not have hired employees; are predominantly financed with contributions from members and donations from individuals; full or significant portion of its income is spend in acting on health issues; operate almost exclusively claimingfor attendances in the public health system and in participation in health councils. Conclusion: NGOs that act in health field in DF 
do very little advocacy work and have their sustainability compromised by infrastructure and funding problems.

Key-words: Right to health; advocacy, health; NGOs.

\section{Introdução}

Desconhece-se a existência de bibliografia sobre o perfil das organizações não governamentais (ONGs) e, especificamente, sobre aquelas que atuam na defesa do direito à saúde (Brito, 2009).O presente estudo se destina a investigar a realidade pouco conhecida do perfil das organizações que atuam no Distrito Federal (DF).

No Brasil, o processo de fundamentação legal e constitucional da política de saúde foi lento. Em um breve exame das constituições republicanas, observa-se que os direitos sociais eram pouco reconhecidos e se limitavam a atribuir competência à União para legislar em matéria de saúde. Somente em 1988 a Constituição Federal afirmou que "a saúde é direito de todos e dever do Estado" (art.196), definindo obrigações, competências e responsabilidades em saúde da União, dos estados, do Distrito Federal e dos municípios (arts. 196 a 200) (Brasil, 1988).

O sistema público de saúde ofertado anteriormente à Constituição de 1988 era considerado deficiente e caótico, havendo grande insatisfação social. As condições de saúde da população eram consideradas críticas, resultado de uma política concentradora, centralizadora, privatizante e ineficaz, expressão do regime político autoritário vigente. O foco da saúde pública era centralizado em campanhas de vacinação e privilegiava a aplicação de recursos públicos em construções e reformas dos hospitais privado, em detrimento do atendimento ambulatorial e preventivo (Alves, 2008).

O movimento da reforma sanitária era composto por "intelectuais, profissionais do sistema de saúde, parcela da burocracia, organizações populares e sindicais em torno da luta da garantia do direito universal à saúde e construção de um sistema único e estatal de prestação de serviços" (Teixeira e Mendonça, 2006, p. 204). Defendiam uma política de saúde universal, equânime, onde o acesso aos serviços e ações de saúde não estivessem atrelados ao trabalho formal. 
Essa mudança de paradigma no âmbito constitucional sofreu forte e decisiva influência do movimento sanitarista, que defendia a idéia da saúde como um direito de todos e dever do Estado (Gohn, 1995), contando com uma ampla participação popular, tendo na realização da $8^{\text {a }}$ Conferência Nacional de Saúde (8 CNS), em 1986, a coroação desse movimento. Nessa Conferência inaugurou-se o processo de participação da sociedade civil nas políticas de saúde, quando foi estabelecido o princípio deque os delegados do segmento de usuários deveriam constituir $50 \%$ da composição dos conselhos e conferências de saúde, em relação aos demais segmentos (trabalhadores da saúde, prestadores de serviço e governo). Seu relatório final serviu de base para a elaboração do capítulo da saúde no texto constitucional de 1988, sendo considerada a pré-constituinte.

Com a promulgação da Constituição Federal de 1988, ficou estabelecido que compete ao Estado garantir a saúde do cidadão e da coletividade, num reconhecimento de que o sujeito é detentor do direito e o Estado o seu devedor. O direito à saúde foi elevado à categoria de direito subjetivo público (Santos, 2005) e a saúde passou a ser um bem jurídico constitucionalmente tutelado.

A participação da comunidade é colocada como uma das três diretrizes da organização do SUS, ao lado da descentralização e do atendimento integral, (Brasil, 1988) e é bastante detalhada na legislação infraconstitucional (Lei no 8.080/90, Lei o 8.142/90, Resolução oㅜ 333/2003 do Conselho Nacional de Saúde (CNS). Seja individualmente ou por meio de associações civis, ela se realiza nasconferências de saúde, em caráter propositivo, e nos conselhos de saúde, em caráter deliberativo (Carvalho, 2007).

Segundo Carvalho (2007, p.45) o termo participação da comunidade é muito mais "amplo, abrangente e profundo do que o simples controle social", pois o controle é somente uma das funções atribuídas à participação da comunidade. A participação é aperfeiçoada por intermédio do princípio do empoderamento, entendido como "processo de capacitação dos indivíduos e comunidades para assumirem maior controle sobre os fatores pessoais, sócioeconômicos e ambientais que afetam a saúde" (WHO, 1998 apud Sicoli e Nascimento, 2003). 
A participação dos cidadãos na construção das políticas públicas, no Brasil, ainda é muito discreta (Carvalho, 2007). A participação plena é complexa, demorada e dá trabalho, pois se trata de um processo lento e gradual. Como diz Carvalho (2007, p. 223), "isto é obra para século!".

Para que se alcance a participação, é necessário que a sociedade se organize e se mobilize e, para tanto, é necessário investir na formação do cidadão, com um ensino de qualidade e com a publicização das informações, capacitando-o à discussão das políticas públicas e ao processo de tomada de decisão e controle, abrindo espaços verdadeiramente democráticos.

O processo de redemocratização, a instauração do Estado Democrático de Direito e a implementação dos mecanismos de democracia direta possibilitaram, assim, a participação mais efetiva das organizações sociais nas decisões sobre a vida em comunidade e impulsionaram a constituição de organizações não governamentais (ONGs), que passaram a desempenhar uma função essencial à afirmação e à garantia dos direitos, processo no qual essas e outras organizações sociais buscavam, inicialmente, a afirmação legal de direitos e, em seguida, sua efetivação, exercendo efetivamente a advocacia.

Para Dallari et al. (1996) a advocacia em saúde origina-se da reivindicação pelo direito à saúde e tem como princípio basilar os direitos básicos positivados juridicamente, ou não positivados, que são desrespeitados ou não garantidos. Ela conceitua advocacia em saúde como sendo

O processo que utiliza conjunto de estratégias políticas visando a promover direitos não respeitados, através de meios legais e éticos, a favor de grupos sociais desfavorecidos ou oprimidos. Assim, a advocacia em saúde desenvolve ações que procuram influenciar autoridades e particulares, sensibilizando-os para carências e necessidades sanitárias diversas (Dallari et al., 1996, p. 593).

Ou, ainda:

Um processo de fortalecimento de cidadãos ou grupos de cidadãos para o exercício reivindicatório de seu direito à saúde, quando não usufruído plenamente, junto às instâncias estatais e não estatais, realizado por instrumentos de persuasão e convencimento (Delduque e Bardal, 2008, p. 70).

Vê-se, pois, similaridade na fala dos diversos autores, que demonstram que a advocacia em saúde é aquela praticada pelos atores sociais, em favor do direito coletivo, ou até mesmo individual, na busca da reivindicação dos direitos básicos em saúde, não garantidos em lei ou não respeitados pelo Estado, por 
intermédio de estratégias políticas ${ }^{1}$ com fins de influenciar a tomada de decisão das autoridades.

Demonstra-se acertada a visão de Dallari et al (1996) quando diz que a conceituação de advocacia em saúde está permanentemente em aberto, pois a sua complementação se efetiva na prática da cidadania e no seu empoderamento, por meio da informação e da educação. Implica no aprimoramento dos instrumentos de participação social e no aperfeiçoamento do SUS, e sua ação prática supõe a participação ativa dos atores sociais engajados na luta pela saúde e no uso correto dos instrumentos ${ }^{2}$ da advocacia em saúde.

Baseado nos estudos desenvolvidos por Canel e Castro (2008) e Torronteguy e Raupp (2008), pode-se inferir que o processo da advocacia em saúde se desenvolve em diversas etapas, a saber:

1) Identificação do objeto da ação;

2) Diagnóstico da situação e a análise das variáveis;

3) Formulação de estratégias e definição dos passos da ação política;

4) Apresentação das estratégias aos beneficiários e escolha;

5) Aplicação da estratégia escolhida e

6) Avaliação contínua dos resultados e eventual reformulação da estratégia.

Os obstáculos são diversos e inúmeros ao exercício da advocacia em saúde. Dentre eles, além dos de fundo político, pode-se citar: a dificuldade de articulação entre os diversos atores do controle social; a dificuldade de convencimento e engajamento do cidadão na causa; a falta ou pequena representatividade do grupo; a dificuldade de conseguir espaço na mídia; o risco de os grandes grupos de comunicação se oporem tendenciosamente; o peso da decisão política em detrimento do discurso técnico; a oposição de

\footnotetext{
1 A escolha da estratégia depende também da localização do problema. Dependendo da situação, possíveis estratégias são: a) caso individual; b) ação civil pública; c) iniciativa popular e audiência pública; d) advocacia administrativa dirigida às agências governamentais; e) alteração de leis; e f) monitoramento do legislativo; dentre outras (Canel e Castro, 2008).

${ }^{2}$ Dallari (2003) enumera diversos instrumentos que podem ser utilizados no exercício da advocacia em saúde diante do Judiciário. São eles: o mandado de segurança, (C.F. Art. $5^{\circ}$, LXIX e LXX); o habeas data, (C.F. Art. 5 ${ }^{\circ}$, LXXII);o mandado de injunção, (C.F. Art. 5 ${ }^{\circ}$, LXXI); recorrer ao Ministério Público e à Defensoria Pública e fazer denúncias junto aos Tribunais de Contas.
} 
setores econômicos relevantes, e a necessidade de recursos humanos qualificados (Torronteguy e Raupp, 2008).

Segundo Delduque e Bardal (2008, p. 109), "o reconhecimento de direitos sociais e sua realização ocorrem precedidos de ações transformadoras, que alteram a estrutura estabelecida".

De qualquer forma, a atuação das ONGs e as ações desenvolvidas na defesa do direito à saúde são essenciais para a afirmação da cidadania e na efetivação dos direitos sociais. O entendimento dos mecanismos da participação social e dos instrumentos disponíveis para a advocacia em saúde contribui para o empoderamento das ONGs. A análise das etapas do processo de defesa do direito à saúde possibilita a escolha das melhores estratégias e propicia o êxito do pleito que beneficia toda a coletividade, fortalecendo o papel social das ONGs.

"A proliferação de iniciativas civis voltadas para a construção de democracias participativas, em oposição ao modelo das democracias liberalrepresentativas predominantes nas sociedades do Norte" (Ramos, 2004, p. 1068) foi fator marcante, nas últimas décadas do Século 20. No Brasil, como se viu, o fortalecimento da sociedade se deu no bojo da resistência à ditadura militar e à repressão política.

Para Gohn (2003, p. 26), nos dias atuais, o movimento popular de saúde se fragmentou e entrou na luta da questão de preços dos convênios, remédios, postos de saúde etc. "Eles têm participado das Conferências Nacionais de Saúde e muitos deles envolveram-se na gestão dos Conselhos de Saúde como representantes dos usuários".

A Associação Brasileira de Organizações NãoGovernamentais (ABONG) as conceitua como organismos não governamentais (sem fins lucrativos), criados pela sociedade civil, pela "vontade autônoma das pessoas, para auxiliar o Estado na consecução de seu objetivo mais importante: garantir o pleno exercício da cidadania e da democracia" (ABONG, sd).

As ONGs são importantes instrumentos de defesa do cidadão e podem se valer de todos os recursos legais para a consecução de suas finalidades. Podendo, inclusive, intentar ações judiciais para fazer valer os direitos previstos na Constituição ou na legislação. 
Estudo do Instituto de Pesquisa Econômica Aplicada (IPEA) e do Instituto Brasileiro de Geografia e Estatística (IBGE), realizado em parceria com a ABONG e o Grupo de Institutos, Fundações e Empresas (GIFE), publicado em dezembro de 2004, constatou que, em 2002,existiam 276 mil fundações e associações sem fins lucrativos no Brasil, empregando 1,5 milhões de pessoas. Em 1996, eram apenas2.800 organizações (IBGE, 2004).

Novo estudo, com os mesmos parceiros e metodologia, publicado em 2008, analisou as fundações privadas e associações sem fins lucrativos no Brasil, identificando as mudanças ocorridas, no período de 2002 a 2005. Em 2008, foram identificadas 338.162 mil fundações privadas e associações sem fins lucrativos. A região Sudeste concentrava a maior parte, $42,4 \%$ ou 143.444 instituições; o Centro-Oeste possuía apenas 6,4\%, ou 21.668; e o DF, $1,3 \%$ ou 4.552 instituições (IBGE, 2008). Essas instituições geravam emprego para 1,7 milhões de pessoas e contavam com um número equivalente de voluntários.

Quanto ao perfil, o levantamento constatou que $35,2 \%$ delas atuam na defesa dos direitos e interesses dos cidadãos; $24,8 \%$ são instituições religiosas; e 7,2\% desenvolvem ações na área da saúde, educação e pesquisa (IBGE, 2008).

Estudos como esses propiciam um conjunto de informações importantes para o melhor conhecimento do papel desempenhado pelas associações civis e as fundações privadas no Brasil. O mundo das organizações sem fins lucrativos reúne um universo importante de atores que exercem um papel fundamental na vida dos cidadãos e merece, portanto, ser melhor conhecido e analisado.

Atualmente, o Brasil possui inúmeras ONGs que atuam na área da saúde, revelando as iniciativas da sociedade civil na elaboração de políticas de saúde. Essa atuação teve papel relevante, nas últimas décadas, nos setores de saúde da mulher, reforma psiquiátrica, pessoas com deficiência, patologias específicas, HIV/AIDS, saúde do trabalhador e outros tantos (Ramos, 2004).

\section{Metodologia}

Trata-se de pesquisa exploratória com a realização de entrevistas e a aplicação de formulários aos dirigentes (diretores ou presidentes) das ONGs que defendem o direito à saúde no DF. 
O levantamento dessas organizações foi realizado no período de 14 de julho a 15 de agosto de 2008, por meio de consultas ao Conselho de Saúde do DF, Conselhos Regionais de Saúde, Internet e diretamente com as organizaçõespor meio de contato telefônico ou por e-mail, tendo sido identificadas 33 ONGs que atuam na defesa do direito à saúde no DF.

Adotaram-se como critérios de inclusão: (i) possuir sede ou filial no DF; (ii) possuir inscrição no Cadastro Nacional de Pessoas Jurídicas do Ministério da Fazenda (CNPJ); (iii) possuir endereço eletrônico (e-mail), (iv) possuir telefone de contato e (v) ter trabalhado com saúde, pelo menos uma vez desde $1^{\circ}$ - de janeiro de 2007.

A pesquisa é parte do projeto intitulado "Capacitação em planejamento e desenvolvimento de políticas de saúde: construindo uma rede colaborativa para favorecer a participação popular", concebido e coordenado pelo Centro de Estudos e Pesquisas de Direito Sanitário (CEPEDISA), de São Paulo, com apoio financeiro da Organização Pan-Americana da Saúde (OPAS), conforme Carta Acordo no BR/LOA/0800006.001. No Distrito Federal a instituição responsável pelo desenvolvimento do projeto foi a Fundação Oswaldo Cruz (FIOCRUZ-Brasília), por intermédio do Programa de Direito Sanitário.

Foram levantados dados gerais da instituição e sobre o entrevistado (dirigente), a infraestrutura, a equipe de trabalho, os recursos financeiros, o campo de atuação e os meios de comunicaçãocom que conta a organização, e suas estratégias de atuação.

\section{Resultados e discussão}

\subsection{Características gerais}

Das ONGs que atuam em saúde no DF, $64 \%$ se localizam na região central de Brasília - e não nas cidades onde reside a maioria da população de baixa renda ${ }^{3}$. A cidade de Ceilândia se destaca das demais, concentrando18\% dessas ONGs.

Esses números podem ser reflexo de uma tendência de maior envolvimento das classes média e média alta, "intelectual", na criação dessas organizações (Oliveira, 2007), e esses estratos residirem, principalmente, no

\footnotetext{
${ }^{3}$ Ceilândia, Cruzeiro, Gama, Guará, Núcleo Bandeirante, Santa Maria, Taguatinga.
} 
Plano Piloto de Brasília. Pode decorrer, ainda, da busca por proximidade com as instituições representativas do Estado (União e Governo do Distrito Federal). Por outro lado, sendo Ceilândia a região do DF com maior densidade demográfica, é natural se destacar como a segunda cidade em número de ONGs, demonstrando a tendência de que a sua distribuição geográfica acompanha a distribuição da população.

A média do tempo de existência das ONGsdo DF é de 16 anos. A primeira ONG foi fundada em 1961 e a última, no ano de 2005, sendo que 64\% delas foram criadas a partir da década de 1990. Destacam-se a década de 90, quando foram criadas 10 ONGs e, principalmente, os anos de 2000 a 2005, quando foram criadas 11 , como as principais épocas de criação de ONGs que atuam na defesa do direito à saúde no DF. Tendência que se reverte a partir de 2005.

Esses números são coerentes com os dados levantados pelas pesquisas do IBGE referidas, que mostram o aumento do número dessas instituiçõesno país, entre 2002 e 2005, o que indica, também, uma tendência de maior atividade na defesa dos direitos e interesses dos cidadãos no período (IBGE, 2008).

As mulheres predominam nos cargos de direção das ONGs estudadas (76\%); sendo que $64 \%$ dos dirigentes estão na faixa etária de 40 a 60 anos e $85 \%$ têm curso superior completo. A maioria dos entrevistados (73\%) está no cargo de direção da ONG, há menos de dez anos.

Apesquisa revelou uma grande disparidadeem relação ao número de associados, com predominância de ONGs com número pequeno e médio de associados. A maioria (73\%) delas tem menos de 500 associados; 12 ONGs (37\%) possuem menos de 100 associados; e 9 (27\%), entre 10 e 49 associados. Duas ONGs apenas podem ser consideradas de grande porte, uma com 5.000 associados e outra com 30.000 .

Verificou-se, ainda, se possuíam endereço eletrônico na internet para divulgarem seu trabalho, pois com os avanços das tecnologias da informação e das comunicações, a Internet constitui um importante espaço de divulgação das atividades desenvolvidas pelas ONGs. Apurou-se que apenas 51,5\% dessas entidades possuem site na Internet. 
Considerando que a maioria das ONGs surgiu após a década de 90, quando esse recurso se democratizou, o uso da Internet ainda é baixo, o que demonstra a necessidade de melhor utilização dessa importante ferramenta de divulgação, requerendo atenção e investimento por parte dessas instituições para a construção de um site próprio para propiciar-lhes maior divulgação de suas ações e facilitar o contato com a sociedade.

\subsection{Infraestrutura}

Em relação ao imóvel onde a instituição exerce suas atividades, identificou-se que 27 ONGs não possuem sede própria (82\%): 12 funcionam em imóvel alugado (36,5\%); outras 12 em imóvel emprestado; e três funcionam na residência do seu presidente (9\%). Destaca-se que, dentre as 12 ONGs que funcionam em sede emprestada, 8 (24\%) desses imóveis são cedidos por órgãos do Governo do Distrito Federal (GDF) e 4 (12\%), por instituições privadas ou pessoas físicas.

Isso é preocupante, pois compromete a sustentabilidade da organização, ao mesmo tempo em que o fato de funcionar em local cedido pelo governo, pode interferir na autonomia e independência da organização, tendo em vista a fala do presidente de uma dessas entidades que confessou essa preocupação, principalmente sobre as decisões tomadas pelo seu representante junto ao Conselho de Saúde do DF.

Verificou-se que $91 \%$ das ONGs possuem computadores com acesso à Internet. No entanto, 33,5\% delas possuem apenas um micro com acesso à rede; outras tantas (33,5\%) possuem de dois a cinco computadores ligados à Internet; e $24 \%$ possuem seis ou mais computadores com acesso à Internet. Nove por cento possuem mais de 20 computadores.

Esse é um fator positivo e concorda com os dados do IBGE sobre acesso à Internet que revelou ser o DF a unidade da federação com o maior percentual de pessoas que acessaram a Internet, $41,1 \%$ da população (IBGE, 2007).

\subsection{Funcionamento}

Constatou-se que $100 \%$ das ONGs funcionam de segunda a sexta-feira, no período matutino e vespertino, enquanto $24,5 \%$ funcionam aos sábados no período da manhã e metade destas no período da tarde. Somente duas funcionam em período integral, de segunda a domingo, pela manhã, tarde e 
noite. A maioria (79\%) não possuem dias e/ou períodos específicos para atendimento de questões referentes à saúde.

Os meios mais utilizados pelo público para entrar em contato com a instituição foram, pela ordem: telefone, pessoalmente e e-mail. Os 33 entrevistados (100\%) citaram as opções "telefone" e "pessoalmente", enquanto $28(85 \%)$ citaram o "e-mail".

\subsection{Equipe}

Com relação à composição da equipe de trabalho, a pesquisa revelou que 30 das 33 organizações estudadas têm sua equipe de trabalho composta fundamentalmente por voluntários, que não recebem qualquer remuneração, enquanto $45 \%$ não possuem nenhum trabalhador contratado e remunerado. Dessas, $61 \%$ possuem entre 1 e 10 voluntários em suas equipes e $12 \%$ possuem mais de 50. Das ONGs que têm trabalhadores contratados em suas equipes, $18 \%$ possuem entre 1 a 3 trabalhadores, e $9 \%$, mais de 51 .

A predominância do trabalho voluntário nas ONGs do DF é uma característica similar à encontrada nas pesquisas do IBGE, que revelaram que, no país como um todo, a maior parte dessas entidades $(79,5 \%)$ não possui sequer um empregado formalmente contratado, e, na Região Centro-Oeste, essa taxa era de $74 \%$. A pesquisa do IBGE mostra também que $12 \%$ das ONGs possui entre 1 e 2 empregados; e somente 1,8\% possuem mais de 50 , sendo que as que atuam em área da saúde são das que mais empregam (IBGE, 2008).

Em relação à formação, observou-se grande diversificação nas modalidades de cursos de graduação e pós-graduação informadas pelas pessoas que compõem a equipe de trabalho das ONGs do DF. Os cursos mais frequentes foram: serviço social (13), pedagogia (13), psicologia (12), fisioterapia (7), medicina (7) e direito (7).

Uma vez que a pesquisa buscou informações específicas sobre as ONGs que trabalham com saúde, exclusivamente ou não, investigou-se a existência de capacitação da equipe de trabalho na área da saúde, observando-se que $40 \%$ das ONGs não propiciam capacitação para os membros da equipe que trabalham com saúde. Das que capacitam, 33\% promovem essa capacitação de forma continuada; $15 \%$, apenas no momento da contratação; e 12\% por demanda dos próprios funcionários. 


\subsection{Recursos financeiros}

Para identificar a natureza e sustentabilidade das fontes de financiamento da instituição, tomou-se como referência o ano de 2007 esolicitou-se sua enumeração, indicando da mais para a menos importante.

Para a maioria das ONGs, as fontes de financiamento mais importantes são a contribuição dos próprios associados (64\%) e doações de pessoas físicas (55\%). Apesar das doações de empresas terem sido citadas por quase a metade dos entrevistados (42\%), essa fonte só foi considerada como mais importante para duasorganizações.

O Ministério da Saúde foi citado por duas ONGs como fonte de financiamento, sendo que outros órgãos governamentais mostraram uma maior participação, alcançando a cifra de 18\%. Uma entrevistada reclamou não só da pequena disponibilidade de recursos públicoscomo da dificuldade de obtê-los, em razão do alto grau de exigência e burocracia envolvido, o que inviabiliza o uso desses recursos pelas ONGs. Quanto ao financiamento propiciado por organismos internacionais, somente três ONGs avaliaram como importante, dentre as cincoque declararam já ter recebido recursos dessa fonte de financiamento.

A parcela dos recursos da instituição destinados a sua atuação no campo da saúde, no último ano fiscal, foi de difícil mensuração. Os entrevistados demonstraram dificuldade em fazê-la, revelando não haver muito planejamento nessa área. De qualquer forma, pode-se evidenciar que, nesse item, $40 \%$ das ONGs gastaram todo o montante de recursos com sua atuação na área da saúde; $21 \%$ tiveram gastos com saúde na faixa de $50 \%$ a $79 \%$ dos seus recursos; dois entrevistados declararam que a ONG não possuía renda e outro declarou que os gastos com saúde não chegavam a $1 \%$ da renda da organização.

\section{6 Áreas de atuação}

Dentre as áreas de atuação das ONGs na defesa do direito à saúde, elencadas pela pesquisa, as mais citadas foram: a reivindicação de atendimentos na rede pública (64\%); seguida da participação comunitária (57\%), principalmente nas conferências e conselhos de saúde; o acesso universal aos serviços de saúde (54\%) e condições de trabalho; criança e adolescente e medicamentos e tratamentos diversos (48\%). 
A obtenção de leitos em UTI; atuação junto a planos de saúde; problemas de saneamento básico e pedidos de providências nas áreas de vigilância epidemiológica e vigilância sanitária (qualidade de alimentos, insumos hospitalares, água) foram as ações menos citadas (9\%). Essa baixa frequência de atuação nessas áreas pode revelar um conhecimento limitado do SUS e de sua importância com reflexo direto na qualidade da saúde, merecendo um estudo mais aprofundado.

Também se buscou descobrir o entendimento dos entrevistados sobre 0 conceito de saúde. Para tanto, foram-lhes apresentadas seis alternativas que deveriam ser colocadas por ordem de importância. A opção mais importante para $84 \%$ dos entrevistados foi 'o perfeito bem-estar físico, mental e social', que é o conceito de saúde da Organização Mundial da Saúde; seguida da alternativa 'ter hábitos de vida saudáveis', com $69 \%$; e 'ter qualidade de vida', com $60 \%$. Dentre as opções as menos citadas (entre 6\% e 24\%), estiveram: 'ter transporte'; 'poder brincar com os filhos ou netos'; 'praticar esportes' e 'ter recursos pessoais e sociais'.

Investigou-se ainda o entendimento do entrevistado sobre como garantir o direito a saúde, apresentando opções de escolha, a exemplo do item anterior sobre conceito de saúde. A alternativa mais apontada foi 'estar previsto na Constituição Federal', com 39\%, demonstrando o entendimento da importância de a saúde ser um bem jurídico constitucionalmente tutelado e considerada um direito fundamental. Em segundo lugar, com 24\%, foi citada 'a existência de políticas públicas em saúde' e, em terceiro, com 12\%, 'ter saneamento básico (água, esgoto, coleta de lixo)'.

\subsection{Meios de comunicação}

Pesquisaram-se, também, os meios de comunicação utilizados pela instituição para divulgar suas ações à sociedade, avaliando seu grau de utilização e importância.

A pesquisa revelou que, mesmo em plena era digital, o bom e velho panfleto não saiu de moda, ficando em primeiro lugar, junto com a Internet, com 73\%, como o meio de comunicação mais utilizado pelas instituições para se comunicar com a comunidade. A televisão também é um meio de comunicação bastante utilizado, ficando apenas 3\% abaixo dos primeiros colocados. Vale ressaltar que, no caso da televisão, vários entrevistados 
informaram que não a destacavam em primeiro lugar devido à dificuldade de acesso e a falta de sensibilidade dos jornalistas para a abertura de espaço.

Mesmo com aproximadamente metade das ONGs (48,5\%) não possuindo site na Internet, ela é reconhecida como um dos mais utilizados e importantes meio de comunicação com a comunidade, juntamente com a televisão, por alcançar um grande número de pessoas, num curto espaço de tempo e produzir grande repercussão, conscientização e mobilização.

A grande utilização do e-mail como um mecanismo de comunicação da comunidade com essas instituições deve-se, provavelmente, a essas mesmas razões. E isso apesar de $9 \%$ das entidades não possuírem um computador com acesso à Internet.

\subsection{Estratégias de atuação}

Com relação às estratégias de atuação para a defesa do direito à saúde utilizadas pelas ONGs entrevistadas, a mais citada foi a opção de 'orientar pessoas' (91\%), seguida das alternativas 'acionar a mídia' (76\%) e 'acionar o Ministério Público' (73\%).

Esses números revelam que importantes ações estratégicas de advocacia que envolvem a participação na formulação das políticas públicas de saúde e no acompanhamento da sua execução orçamentária são pouco praticadas pelas ONGs que atuam na defesa do direito à saúde no DF. Questões como essa merecem um estudo mais aprofundado.

Nesse item, pesquisou-se a percepção que os entrevistados têm sobre a participação da sua instituição no processo de formulação e/ou execução de políticas públicas de saúde e em qual esfera de poder têm atuado. A maioria (66\%) entende que o seu nível de participação abrange o DF e $24 \%$ informaram que participam desse processo também a nível nacional. Sendo que $21 \%$ dos entrevistados reconheceram que não participam desse processo.

Por fim, pesquisou-se a percepção dos entrevistados sobre a abrangência do impacto das ações desenvolvidas pela sua ONG na área da saúde. A maioria (76\%) entende que a abrangência das ações desenvolvidas limita-se ao DF; quase a metade (48\%) entende que tem alcance nacional, e $15 \%$ reconhecem que suas ações produzem impacto em outros países.

\section{Conclusão}


A ativa participação social foi fundamental na construção do texto constitucional, principalmente no que se refere ao direito à saúde.

A Constituição Brasileira de 1988 inclui, entre os fundamentos do Estado Brasileiro, a cidadania e a dignidade da pessoa humana. $O$ direito à saúde foi elevado à categoria de direito subjetivo público e ficou estabelecido que compete ao Estado garantir a saúde do cidadão e da coletividade. Houve o reconhecimento de que o cidadão é detentor do direito e o Estado o seu devedor.

A participação da comunidade foi colocada como uma das três diretrizes da organização do SUS, a ser exercida por intermédio dos conselhos e conferências de saúde, mas essa participação dos cidadãos na construção das políticas públicasainda é muito discreta. É necessário investir na formação desses cidadãos, empoderando-os, capacitando-os à discussão das políticas públicas e ao processo de tomada de decisão e controle, para que se consolide a democracia participativa.

A consolidação da redemocratização do país impulsionou a criação de ONGs, que passaram a desempenhar uma função essencial à afirmação e à garantia daqueles direitos, em especial pela ampliação de ações de advocacia em saúde, isto é, da atuação em favor da saúde desenvolvida por elas, visando influenciar as autoridades por meio de estratégias políticas bem planejadas.

Dessa forma, entende-se que a concretização do direito à saúde tem sido grandemente dependente da participação popular e do exercício da cidadania e que a atuação das ONGs e as ações de advocacia em saúde são essenciais para a afirmação da cidadania e da efetivação dos direitos na área da saúde. O entendimento dos mecanismos da participação social e dos instrumentos disponíveis para a advocacia em saúde contribui para o fortalecimento do papel das ONGs.

Por reunirem um universo importante de atores que exercem um papel fundamental na vida dos cidadãos, esse papel merece ser melhor conhecido e analisado.É importante, também, que as ONGs que atuam na defesa do direito à saúde possam se autoconhecer, identificar caminhos para o seu fortalecimento e para aperfeiçoar sua participação na formulação e controle das políticas públicas de saúde. 
Nossos resultados mostram que as ONGs que atuam na defesa do direito à saúde no DF ainda não exercem esse papel em sua complexidade.

São instituições fundadas principalmente a partir da década de 1990 mas não depois de 2005; estão localizadas de forma concentrada em duas cidades do DF (Brasília e Ceilândia); em sua maioria não possuem sede própria e têm um número pequeno ou médio de associados (73\% tem menos de 500 associados).

A grande maioria tem uma equipe composta predominantemente por voluntários, sendo que cerca da metade não possui empregados contratados. Nessas equipes predominam as mulheres e os profissionais com curso superior. Quase todas dispõem de computadores e têm acesso à internet.

Dois terços financiam-se com recursos de contribuições de associados e de pessoas físicas. Cerca de metade recebe doações de empresas, mas para apenas duas delas essa é uma fonte importante de recursos. Somente $18 \%$ recebem recursos de órgãos governamentais e menos de $10 \%$ de organismos internacionais. A maioria delas destina totalmente ou a maior parte de seus recursos ao financiamento de sua atuação em saúde.

Atuam principalmente na reivindicação de atendimentos na rede pública e participando de conselhos e conferências de saúde. Os meios mais utilizados pelo público para entrar em contato com essas ONGs são o telefone, o e-mail e pessoalmente, enquanto elas utilizam principalmente materiais gráficos e a internet para se comunicar com seu público.

Dois fatos preocupantes ressaltam desse quadro: a não criação de novas ONGs com atuação em saúde, no DF, a partir de 2005, depois de um importante crescimento o seu número na década e meia que se sucedeu à promulgação da Constituição de 1988; e a presença de um conjunto de fatores que comprometem a sustentabilidade das organizações, entre os quais o pequeno porte da maioria delas, a ausência de sede própria e a dependência de contribuições de associados e de doações de pessoas físicas para financiarem suas ações.

Passados vinte e cinco anos da promulgação da Constituição Federal brasileira, ganha relevo a necessidade de um maior conhecimento sobre 0 papel das ONGs da saúde. Nesse sentido, os resultados da pesquisa são instigantes e evidenciam a necessidade da discussão do papel e da atuação 
das ONGs de saúde, que necessita ser aprofundada por outros estudiosos e especialistas daSaúde Pública e do Direito Sanitário.

Espera-se que as informações aqui apresentadas sejam úteis à sociedade e contribuam para ampliar o conhecimento sobre as ONGs que atuam na defesa do direito à saúde, em especial aquelas localizadas no DF.

\section{Referências}

ALVES, Sandra Mara Campos. Processo de participação da sociedade civil nas consultas públicas realizadas pela Agência Nacional de Vigilância SanitáriaAnvisa. Brasília: UnB, 2008. 243 p. Dissertação (Mestrado) - Programa de PósGraduação em Política Social, Departamento de Serviço Social, Instituto de Ciências Humanas, Universidade de Brasília, Brasília, 2008.

ASSOCIAÇÃO BRASILEIRA DE ORGANIZAÇÕES NÃO GOVERNAMENTAIS - ABONG. São Paulo: ABONG, s/d. [on line] Disponível na Internet na URL: http://www.abong.org.br/final/faq pag.php?faq=12189 (Consultado em 5 set. 2009).

BRASIL. Constituição da República Federativa do Brasil (1988). Brasília: Câmara dos Deputados. [on line] Disponível na Internet na URL: http://www2.camara.gov.br/legislacao/constituicaofederal.html (Consultado em 5 set. 2009).

Relatório Final da $8^{a}$ Conferência Nacional de Saúde. Brasília: Ministério da Saúde, Conselho Nacional de Saúde,1986. [on line] Disponível na Internet na URL: http://portal.saude.gov.br/portal/arquivos/pdf/8 CNS Relatorio\%20Final.pdf(Co nsultado em 7 set. 2009).

BRITO, Clênio M. Perfil das ONGs do Distrito Federal que atuam na defesa do direito à saúde. Brasília: Fiocruz, 2009. (Monografia) Especialização em Direito Sanitário. Disponível na Internet na URL: http://www.brasilia.fiocruz.br/prodisa/?page $i d=171$ (Consultado em 29 set. 2009).

CANEL, Regina Célia; CASTRO, Cláudio Gastão Junqueira. A advocacia em saúde como uma estratégia para a promoção da saúde. Revista de Direito Sanitário, São Paulo, 9(1):74-85, mar./jun., 2008. ISSN: 1516417-9.

CARVALHO, Gilson de Cássia Marques. Participação da comunidade na saúde. Passo Fundo: IFIBE/CEAP, 2007. ISBN: 978-85-991-8439-4.

DALLARI, Sueli Gandolfi et al. Advocacia em saúde no Brasil contemporâneo. Revista de Saúde Pública, São Paulo, 30(6):592-601, 1996. ISSN: 0034-8910.

DELDUQUE, Maria Célia; BARDAL, Priscila Ariede Petinuci. Advocacia em Saúde: prática cidadã para a garantia do direito à saúde - o caso do projeto de lei complementar no 01/2003 Revista de Direito Sanitário, São Paulo, 9(1):107122, mar./jun., 2008. ISSN: 1516417-9. 
GOHN, Maria da Glória. História dos movimentos e lutas sociais: a Construção da cidadania dos brasileiros. São Paulo: Edições Loyola, 1995. ISBN: 85-1501154-9.

Movimentos sociais na atualidade: manifestações e categorias analíticas. In: GOHN, Maria da Glória (Org.), Movimentos sociais no início do século XXI: antigos e novos atores sociais, Petrópolis, RJ: Vozes, 2003. p. 1332. ISBN: 978-85-326-2832-9.

INSTITUTO BRASILEIRO DE GEOGRAFIA E ESTATÍSTICA - IBGE. Acesso à Internet e posse de telefone móvel celular para uso pessoal - 2005. Pesquisa Nacional por Amostra de Domicílios - PNAD. Rio de Janeiro : IBGE, 2007. ISBN: 978-85-240-3932-4.

As Fundações Privadas e Associações sem Fins Lucrativos no Brasil - 2002. Estudos e Pesquisas - Informação Econômica, Rio de Janeiro, (4), 2004. ISBN 978-85-240-3793-8.

As Fundações Privadas e Associações sem Fins Lucrativos no Brasil - 2005. Estudos e Pesquisas - Informação Econômica, Rio de Janeiro, (8), 2008. ISBN 978-85-240-4022-1.

OLIVEIRA, Wagner. A relevância dos movimentos sociais e ONGs na sociedade brasileira. Web Artigos, 2007. [on line] Disponível na Internet na URL: http://www.webartigos.com/articles/1208/2/a-relevancia-dos-movimentossociais-e-ongs-na-sociedade-brasileira/pagina2.html(Consultado em 9. set. 2009).

RAMOS, Sílvia. O papel das ONGs na construção de políticas de saúde: a AIDS, a saúde da mulher e a saúde mental. Revista Ciência \& Saúde Coletiva, Rio de Janeiro, 9(4):1067-1078, out./dez., 2004. ISSN 1413-8123.

SANTOS, Lenir. Saúde: conceito e atribuições do Sistema Único de Saúde.Jus Navigandi, Teresina, 10(821), 2 out. 2005. [on line] Disponível na Internet na URL: http://jus.com.br/artigos/7378(Consultado em 8 set. 2009).

SíCOLI, Juliana Lordello; NASCIMENTO, Paulo Roberto. Promoção de saúde: concepções, princípios e operacionalização. Interface - Comunicação, Saúde, Educação, Botucatu, 7(12):101-122, fev., 2003. ISSN 1807-5762.

TEIXEIRA, Sonia Fleury e MENDONÇA, Maria Helena Magalhães. Reformas sanitárias na Itália e no Brasil: comparações. In: TEIXEIRA, Sonia Fleury (Org.) Reforma Sanitária: em busca de uma teoria. São Paulo: Cortez, 2006, p. 193232. ISBN: 85-249-0189-6.

TORRONTEGUY, Marco Aurélio Antas; RAUPP, Luciane. Obstáculos políticos à advocacia sanitária no Brasil: a pesquisa com células-tronco embrionárias. Revista de Direito Sanitário, São Paulo, 9(1):86-106, mar./jun., 2008. ISSN: 1516417-9.

Recebido para publicação em 18 de janeiro de 2013. Versão final em 21 de agosto de 2013. 